\title{
Modeling of the Global Water Cycle - Analytical Models
}

\author{
Yongqiang Liu \\ Forestry Sciences Laboratory \\ USDA Forest Service \\ 320 Green St., Athens, GA 30602, USA \\ Roni Avissar \\ Department of Civil and Environmental Engineering \\ Duke University \\ Durham, NC 27708, USA
}

Keywords: Analytical model, water cycle, persistence, land-atmosphere interaction and feedback

\begin{abstract}
Both numerical and analytical models of coupled atmosphere and its underlying ground components (land, ocean, ice) are useful tools for modeling the global and regional water cycle. Unlike complex three-dimensional climate models, which need very large computing resources and involve a large number of complicated interactions often difficult to interpret, analytical models are able to provide more direct and intuitive figures of variability and processes in a highly simplified system. They can be a good and efficient alternative modeling tool, especially for studying continental water cycle. This article describes the analytical models developed based on the soil and atmospheric water and energy conservation equations. A fourth-order model is used to illustrate the perturbation equation, solutions, and physical interpretation. Our understanding of some water cycle variability issues, including timescale, persistence, and major physical parameters and processes, obtained from the analytical models is presented.
\end{abstract}

\section{Introduction}

One of the major improvements in our understanding of the global and regional water cycle during the past three decades was the realization of the importance of soil memory (especially soil moisture) to seasonal and interannual variability of continental water cycle. Atmospheric manifestations of variability in the hydrological cycle occur at multiple time scales, including cloud and precipitation events related to synoptic systems (daily and weekly), floods and droughts (seasonal), the Southern Oscillation (interannual), and climate shifts (decadal). Because an anomaly signal in the atmosphere alone (that is, isolated from the earth's surface) can only last for a period of about two weeks, variability of the atmospheric hydrological processes at seasonal or longer scales has to be related in some way to the earth's surface, which has longer memory. 
Soil moisture controls water and energy exchanges by providing available water for evapotranspiration and by determining the partition of radiative energy absorbed on the ground surface into sensible and latent heat fluxes (Avissar, 1995). Therefore, anomalies in soil moisture can result in significant changes in atmospheric hydrological and thermal processes by land-atmospheric interactions (e.g., Mintz, 1984; Avissar and Verstraete, 1990; Betts et al., 1996). Furthermore, with the capacity of retaining anomalous signals over months to seasons (e.g., Delworth and Manabe, 1988; Vinnikov et al., 1996), soil moisture can contribute to long-term atmospheric variability over land by passing its relatively slow anomalous signals to the atmospheric hydrological processes.

The importance of soil moisture in the continental water cycle indicates a fundamental difference with the oceanic water cycle, in which the surface fluxes and long-term anomalies are mostly affected by sea-surface temperature (Cane, 1992). This, of course, is due to the fact that the amount of water available for evaporation is unlimited in the ocean, and its thermal capacity is very large.

Three-dimensional general circulation models (GCMs) and regional climate models (RCMs) have been very useful tools for studying soil moisture variability and its interactions with atmospheric processes. Coupled with detailed land-surface parameterizations (e.g., Dickinson et al. 1993; Sellers et al. 1986; Xue et al. 1991), these models are able to simulate long-term variations of atmospheric and soil states, hydrological and thermal processes, and water and energy fluxes at the ground surface. The simulation outputs are used to analyze the water cycle variability and its causes (e.g., Delworth and Manabe, 1989; Bonan, 1994; Koster and Suarez, 1995). Experiments of model's response to initial soil moisture anomalies provide evidence for the possible roles of soil moisture in onset and/or intensification of floods and droughts (e.g., Giorgi et al., 1996) and local water cycle processes (Avissar and Liu, 1996), and improvement of predictability of the water cycle variability (e.g., Schlosser and Milly, 2002; Dirmeyer, 2003).

Considering that three-dimensional climate models need very large computing resources and involve a large number of complicated interactions often difficult to interpret, analytical models can be a good and efficient alternative to study the mechanisms underlying the global water cycle, especially in continental areas. Many analytical models have been developed, based on soil water balance equation (e.g., Delworth and Manabe, 1988; Rodriguez-Iturbe et al., 1991; Entekhabi et al., 1992; Huang et al. 1996), complete water and energy balance equations of the land-atmosphere system (e.g., Brubaker and Entekhabi, 1996; Liu and Avissar, 1999b), or something in between (e.g., Liu et al., 1992). Analytical models including interactions between soil moisture and the atmospheric planetary boundary layer (PBL) processes also have been developed (e.g., Eltahir, 1998; Findell and Eltahir, 2003).

Analytical models for the land-atmosphere water and energy system have varying level of complexity. The most basic model is a first-order system composed of a 
conservation equation for water or heat of the soil or the atmosphere. The most important first-order system is the soil water conservation, which describes the internal variability of soil water and the effects of external processes. The most complete system is the forthorder one, which describes internal variability of each of the four system components and interactions between them. Liu and Avissar (1999b or LA99) discussed a forth-order system and compared it with various lower-order systems.

This article describes analytical models of the land-atmosphere energy and water balance and their applications to studying continental water cycle variability. The models are first introduced in Section 2, with a focus on the system described in LA99. The solutions and dependence on the water exchange are presented in Sections 3 and 4, respectively. Applications of the models to a number of issues, including water cycle time scales, persistence, and physical mechanisms, are described in Section 5. A summary is given in the final section.

\section{The Models}

\subsection{Framework}

Figure 1 shows a schematic representation of the continental water and energy cycle system. The atmospheric component is assumed to consist of an air column of height $h_{a}$, and the soil component consists of an active layer and a sublayer. Because the soil depths at which thermal and hydrological processes are active are not necessarily identical, they are differentiated between a thermally active layer of depth $d_{T}$ and a hydrologically active layer of depth $d_{w}$. To account for possible diffusion of heat and moisture at the bottom of the active soil layer, soil sublayers of depth $d_{T o}$ and $d_{w o}$ are defined for thermal and hydrological processes, respectively.

The atmosphere is characterized by its temperature, $T_{a}$, and its specific humidity, $q_{a}$. Similarly, the soil is characterized by its temperature, $T_{g}$, and its volumetric soil-water content, $W_{g}$, for the active layer, and by a constant temperature, $T_{g o}$, and a constant volumetric soil-water content, $W_{g o}$, for the sublayer. The four state variables are determined by the energy and water conservation equations of the soil and atmosphere, and interact with each other through fluxes of radiation, sensible heat flux, latent heat flux (evaporation), and precipitation. Exchanges through diffusion and runoff also affect temperature and moisture of the soil active layer.

\subsection{Basic Equations}

The fourth-order continental water and energy cycle (Liu and Avissar 1999b, hereafter referred to as LA99) consists of the following set of heat and water conservation equations: 


$$
\begin{aligned}
& C_{a} \frac{d T_{a}}{d t}=R_{a}+H+L P, \\
& M_{a} \frac{d q_{a}}{d t}=E-P, \\
& C_{g} \frac{d T_{g}}{d t}=R_{s}-H-L E+K_{T}\left(T_{g o}-T_{g}\right), \\
& M_{g} \frac{d W_{g}}{d t}=P-E-F+K_{w}\left(W_{g o}-W_{g}\right),
\end{aligned}
$$

where $K_{T}=2 D_{T} C_{g} /\left[d_{T}\left(d_{T}+d_{T 0}\right)\right]$ and $K_{w}=2 D_{w} M_{g} /\left[d_{w}\left(d_{w}+d_{w 0}\right)\right]$ are forcing factors to restore thermal and hydrologic anomalies to the normal states, respectively; $C_{a}\left(=\rho_{a} c_{p} h_{a}\right)$ and $C_{g}\left(=\rho_{g} c_{g} d_{T}\right)$ are the heat capacity of the atmosphere and the soil, respectively $\left(c_{p}\right.$ is specific heat of air at constant pressure, $c_{g}$ is specific heat of the ground, $\rho$ is density, and subscripts $a$ and $g$ indicate atmosphere and ground); $M_{a}\left(=\rho_{a} h_{a}\right)$ and $M_{g}\left(=\rho_{w} d_{w}\right)$ are masses of the air column and of a column of water of depth $d_{w}$ per unit area; $R_{\mathrm{a}}$ and $R_{s}$ are the radiation balance of the atmosphere and the land surface; $H$ and $E$ are the sensible heat flux and evaporation on the land surface; $P$ and $F$ are precipitation and runoff; $D_{T}$ and $D_{w}$ are the soil thermal and hydraulic diffusivity; and $L$ is the latent heat. It should be mentioned that this is a onedimensional, vertical representation of land-atmosphere interaction, centered over a land surface, and vegetation and snow are neglected.

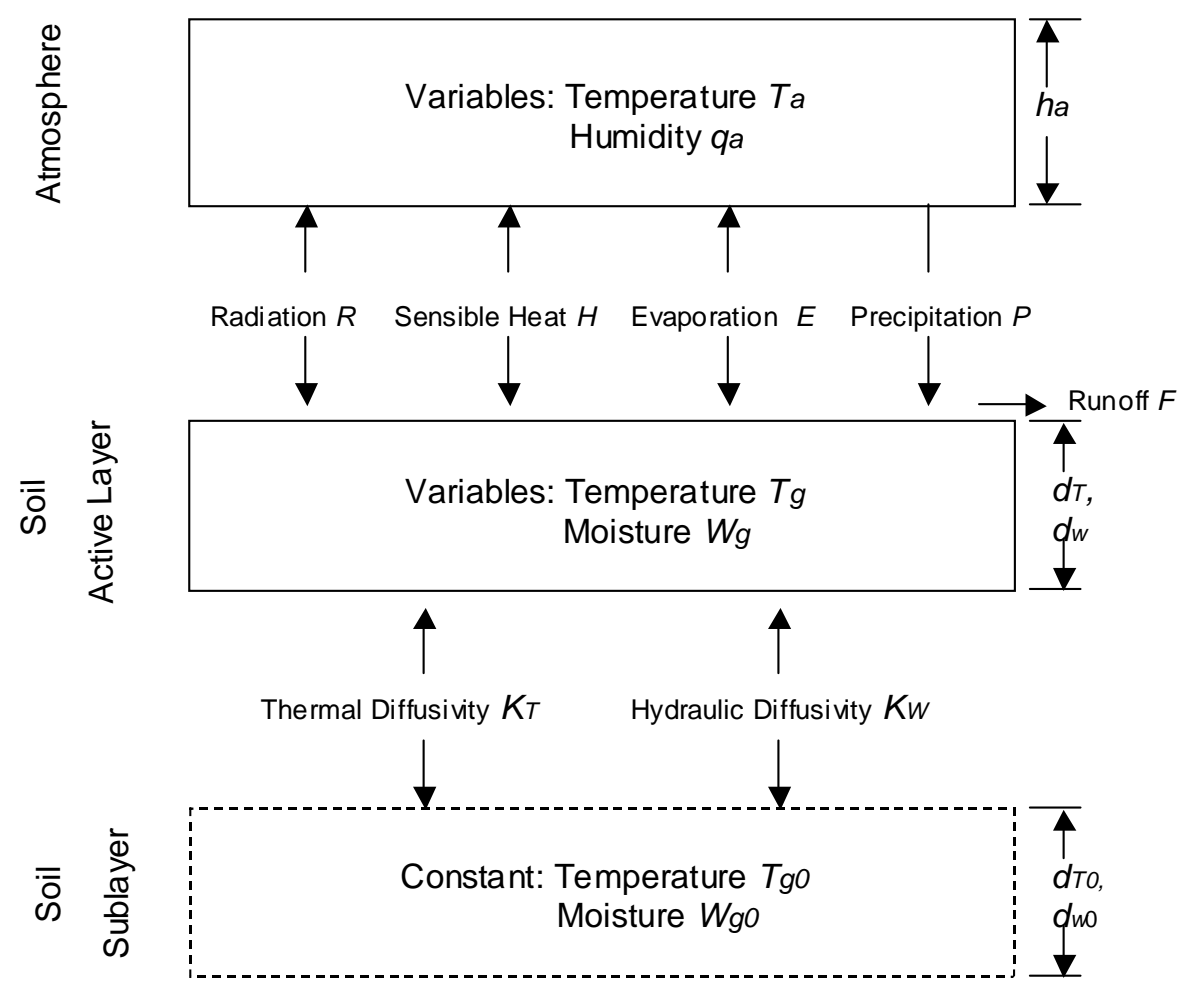

Figure 1 Schematic representation of the continental water and energy cycle system 


\subsection{Fluxes}

The fluxes in Eqs.1-4 are calculated by the following formulas:

$$
\begin{aligned}
& R_{s}=\left[1-\alpha_{a}(1-n)-\alpha_{c} n-A_{a}-C_{r} n\right] S_{o}-\varepsilon \sigma T_{g}^{4}+n \varepsilon \sigma T_{a}^{4}, \\
& R_{a}=\left(A_{a}+C_{r} n\right) S_{o}+n \varepsilon \sigma T_{g}^{4}-n \varepsilon \sigma T_{a}^{4}-n \varepsilon \sigma T_{a}^{4}-(1-n) G \sigma T_{g}^{4}, \\
& H=H_{0}\left(T_{g}-T_{a}\right), \\
& E=\eta E_{p}=\eta E_{0}\left[q_{s}\left(T_{g}\right)-q_{a}\right], \\
& P=C_{1} W_{a} \exp \left(-C_{2} / R_{h}\right)^{C 3}, \\
& F=\eta(P-E)
\end{aligned}
$$

The radiative fluxes are calculated following Paltridge (1974). The first term on the right-hand side of Eq.5 is the net shortwave radiative flux at the land-surface, where $S_{o}$ is the incident shortwave radiation at the tropopause, $\alpha_{a}$ and $\alpha_{c}$ are the planetary albedo for clear sky and for cloudy atmosphere, $A_{a}$ is the atmospheric absorption of shortwave radiation, and $n$ is the cloud fraction. The next two terms together represent the net longwave radiative fluxes. The atmosphere is assumed to be opaque to longwave radiation at all wavelengths other than in the atmospheric window $(7.5-12.5 \mu \mathrm{m})$, where absorption is assumed negligible. In this model, longwave energy transfer occurs only in the atmospheric window and, therefore, it is the only flux that needs to be considered. The constant $\sigma$ is the StefanBoltzmann constant, and $\varepsilon$ is the fraction of total blackbody radiation at normal earth temperatures contained within the wavelengths of the atmospheric window. Note that this model represents an averaging condition over time and land area and, therefore, the cloud fraction, $n$, is never zero.

The first term on the right-hand side of Eq.6 is the net shortwave radiative flux of the atmosphere. In this term, the factor $C_{r}$ accounts explicitly for the extra shortwave absorption in clouds. The second and third terms represent the net longwave absorption in clouds resulting from exchange of radiant energy with the Earth's surface. In the clear atmosphere, the absorption bands of water vapor become less opaque with increasing height and decreasing water vapor concentration. In effect, the atmospheric window expands with increasing altitude so that each atmospheric level loses energy directly to space. Since the average temperature lapse to the tropopause is close to adiabatic as a result of mixing, on the average, the temperature at any level bears a fairly constant relation to the surface temperature. Thus, the total longwave loss from the clear-sky troposphere is likely to be proportional to surface blackbody radiation. This concept is the basis of the last term in Eq.6, which contains a simple constant of proportionality G, that was found to be about 0.38 (on average) for a large number of studied typical cases. A detailed discussion of the philosophy 
behind this scheme, as well as of the values assigned to each of its variables, are given in Paltridge (1974), and are not repeated here for brevity

In the bulk flux formulas for sensible heat and evaporation (Eqs.7-8), $H_{0}=\rho_{a} C_{p} C_{D T} V$ and $E_{0}=\rho_{a} C_{D W} V ; C_{D T}$ and $C_{D W}$ are the sensible heat and water drag coefficients, respectively, which are strongly dependent upon land surface, and atmospheric dynamic and thermal properties (e.g., vegetation cover and stability); $V$ is the wind speed in the atmospheric surface layer; $E_{p}$ is the potential evaporation; $q_{s}\left(T_{g}\right)$ is the saturated air specific humidity at temperature $T_{g}$; and $\eta=W_{g} / W_{\mathrm{s}}$ is the soil wetness, with $W_{\mathrm{s}}$ being the volumetric soil-water content at saturation.

Precipitation is arguably the most important and complex hydrological process in the water cycle and the land-atmosphere interactions system. Both atmospheric dynamics and local water and heat exchanges in the land-atmosphere system can contribute to the essential conditions for the formation of precipitation (i.e., ascending motion of air masses, stratified instability, and water vapor supply). Because the model proposed here does not simulate atmospheric dynamics, precipitation is parameterized with a simple formula, which only accounts for the variances of atmospheric moisture and sensible heat caused by landatmosphere interactions. The precipitation parameterization (Eq.9) is based on the premise that at a given geographic location and a given general circulation pattern, precipitation is mostly related to atmospheric water vapor content, $W_{a}$, and the relative humidity, $R_{h}$, of the entire air column. This formula is formed by applying dimensional analysis to relations between precipitation and these two factors. $C_{i}(i=1,2,3)$ are empirical constants. In this model, $C_{2}=0.5$ and $C_{3}=4.5$. With its relatively simple form, this parameterization certainly has a very limited capacity in reproducing observed precipitation statistics, which would affect the analysis with the fourth-order model. However, $C_{1}$ is derived from the ratio of climatological evaporation to precipitation, namely $r_{E P}=\bar{E} / \bar{P}$, which therefore adds a restraint in estimating average rainfall. Runoff (Eq.10) is proportional to the net soil water gain, and to ratio of soil moisture to its saturation value. The linear relation between runoff and both the net water gain and the ratio is valid mostly for calculation of runoff process at seasonal or longer scales.

\subsection{Perturbation equation}

The perturbation approach (Holton 1979) is used to linearize the equations of the model. Accordingly, any variable $\phi$ is separated into a mean $\bar{\phi}$ and a perturbation $\phi^{\prime}$. Assuming that the perturbations are small as compared to the means, any terms including the product of two or more perturbations are much smaller than a term that includes only one or no perturbation. Thus, for instance, the radiation emitted by a black body at a temperature $T$ is given by $\sigma T^{4}=\sigma\left(\bar{T}+T^{\prime}\right)^{4} \approx \sigma\left(\bar{T}^{4}+4 \bar{T}^{3} T^{\prime}\right)$.

The perturbation equations for the sensible heat and evaporation fluxes are: $H^{\prime}=$ $H_{0}\left(T_{g}{ }^{\prime}-T_{a}{ }^{\prime}\right)$ and $E^{\prime}=\bar{\eta} E_{0}\left(\Delta_{g} T_{g}{ }^{\prime}-q_{a}{ }^{\prime}\right)$, where $\Delta_{g}=d q_{s} /\left.d T\right|_{T=T g}$. To develop a perturbation 
equation for precipitation, the atmospheric water content in Eq.9 is first substituted with the product of the specific humidity with the mass of the atmosphere, and the relative humidity by the ratio of the specific humidity to the specific humidity at saturation. Subsequently, we differentiate the expression and assume that the perturbation of a quantity is approximately equal to its differential value, and that the average is expressed by the non-differential value. As a result, $P^{\prime} / \bar{P}=P_{1} q_{a}{ }^{\prime}-P_{2} T_{a}{ }^{\prime}$, where $P_{1}=\left[1+C_{3}\left(C_{2} / \bar{R}_{h}\right) C^{C_{3}}\right] / \bar{q}_{a}, P_{2}=C_{3}\left(C_{2} / \bar{R}_{h}\right) C_{3} \Delta_{a} / \bar{q}$ as, and $\Delta_{a}=d q_{s} /\left.d T\right|_{T=T a}$. The perturbation of cloud amount is related to the precipitation perturbation as follows: $n^{\prime} / \bar{n}=P^{\prime} / \bar{P}$. The perturbation of the radiative fluxes is given by: $R s^{\prime}=\left(\varepsilon \bar{n} \Delta_{L a}+R_{s 1} P_{2} \bar{n}\right) T_{a}{ }^{\prime}-\varepsilon \Delta_{L g} T_{g}{ }^{\prime}-R_{s 1} P_{1} \bar{n} q_{a}{ }^{\prime}$ and $R_{a}{ }^{\prime}=-\left(R_{a 1}+R_{a 3} P_{2} \bar{n}\right) T_{a}{ }^{\prime}+R_{a 2} T_{g}{ }^{\prime}+R_{a 3} P_{1} \bar{n} q_{a}{ }^{\prime}$, where $\quad R_{s 1}=\left(\alpha_{c}-\alpha_{a}-C_{r}\right) S_{o}-\varepsilon \sigma \bar{T}_{a}^{4}, \quad R_{a 1}=\left(\varepsilon^{+} \varepsilon^{\prime}\right) \bar{n} \Delta_{L a}, \quad R_{a 2}=\left[\left(\varepsilon^{+} G\right) \bar{n}-G\right] \bar{n} \Delta_{L g}$, $R_{a 3}=C_{r} S_{0}-\left(\varepsilon^{+} \varepsilon^{\prime}\right) \sigma \bar{T}_{a}{ }^{4}+(\varepsilon+G) \sigma \bar{T}_{g}{ }^{4}$, and $\Delta_{L i}=d\left(\sigma \bar{T}_{i}{ }^{4}\right) / d \bar{T}_{i},(i=a, g)$.

Using these flux perturbations, the heat and water conservation equations (Eqs.1-4) can be written:

$$
\frac{d}{d t} \boldsymbol{Y}=\boldsymbol{C} \boldsymbol{Y}
$$

where $\boldsymbol{Y}=\left(\boldsymbol{Y}_{i}\right)=\left(T_{a}^{\prime} / \bar{T}_{a}, q_{a}^{\prime} / \bar{q}_{a}, T_{g}{ }^{\prime} / \bar{T}_{g}, W_{g}{ }^{\prime} / \bar{W}_{g}\right) \quad$ and $\boldsymbol{C}=\left(c_{i j}\right)=\boldsymbol{I}_{1} \boldsymbol{A} \boldsymbol{I}_{2 .} \boldsymbol{I}_{1}$ is a diagonal matrix with elements $\left[\left(C_{a} \bar{T}_{a}\right)^{-1},\left(M_{a} \bar{q}_{a}\right)^{-1},\left(C_{g} \bar{T}_{g}\right)^{-1},\left(M_{g} \bar{W}_{g}\right)^{-1}\right], \mathbf{I}_{2}$ is a diagonal matrix with elements $\left[\bar{T}_{a}^{-1}, \bar{q}_{a}^{-1}, \bar{T}_{g}^{-1}, \bar{W}_{g}^{-1}\right]$, and $A=\left(a_{i j}\right)$ is a coefficient matrix. This equation represents a set of linear homogeneous differential equations with constant coefficients, whose linearly independent solutions can be written:

$$
\boldsymbol{Y}_{i}(t)=\sum_{j=1}^{4} P_{i j}(t) e^{\lambda j t}
$$

where $\lambda_{j}=\left(\lambda_{r}\right)_{j}+i\left(\lambda_{i}\right)_{j}(j=1,4)$ are roots of the characteristic equation of Eq.12 given by:

$$
\sum_{k=0}^{4} d_{k} \lambda^{4-k}=0
$$

The parameter $\lambda_{r}$ is the perturbation growth rate, and the reciprocal of its absolute value is the e-folding time. If $\lambda_{r}<0$, the e-folding time is also called damping time. In Eq.12, $P_{i j}(t)$ is a polynomial whose order is equivalent to the number of equal roots. In Eq.13, $d_{k}$ are constant coefficients, with $d_{0}=1$ and $d_{1}=-\sum_{k=0}^{4} a_{k k}$.

\subsection{Orders of models}


Eq.11 is a fourth-order analytical model of the continental water and energy cycle system. It contains all interactions (couplings) between the land and the atmosphere, and between hydrological and thermal processes. By assuming no disturbance with soil moisture in the fourth-order model, a third-order model can be obtained. There are no interactions between soil moisture and other model variables. Similarly, three other third-order models can be obtained by assuming no disturbance with soil temperature, air humidity, or air temperature in the fourth-order model. Four second-order models can be obtained by assuming no disturbance with any two of the four system variables. Finally, by assuming no interactions among the four system variables, the fourth-order model becomes four independent first-order models, each of which contains only one of the four variables. In these cases, the variation of the disturbance in the models is caused by self-feedback.

\subsection{Statistical-Dynamical Models}

Delworth and Manabe (1988) described a first-order model of soil water balance equation with a stochastic forcing. Precipitation usually has a much faster pace than soil moisture, suggesting that variation of precipitation could be expressed as "white noise", $z(t)$. Soil moisture can be expressed as "red noise", $y(t)$, which is the output of the following firstorder Markov process:

$$
d y(t) / d t=-\lambda y(t)+z(t)
$$

The stochastic process $z(t)$ can be simulated with observed precipitation series. The solution of this equation indicates the role of the external forcing in variability of soil moisture.

In another first-order model of soil water balance described by Rodriguez-Iturbe et al. (1991), precipitation is expressed as:

$$
P(w)=P_{a}[1+f(w, \Omega)]
$$

where $P_{a}$ is the advective precipitation resulting from the atmospheric horizontal transport of water vapor from outside, and $\Omega$ is a Gaussian noise of atmospheric processes related to the internal precipitation resulting from the vertical transport of water vapor from the evaporation on the ground. $P$ is related to soil moisture $w$.

The fourth-order model described by Brubaker and Entekhabi (1996) consists of four stochastic ordinary differential equations in soil moisture, soil temperature, mixed-layer humidity, and mixed-layer potential temperature. The variations of the system are determined by deterministic steady forcing and white-noise perturbation processes. The solution is a physically consistent joint probability distribution.

\section{Solutions}


Table1 lists the various atmospheric and soil conditions needed to calculate the elements of the matrix $C$. These values are assumed to be representative of annual conditions under current climate over land. The values for the radiative flux are adopted from Paltridge (1974). A few values of parameters related to other processes are taken from the BiosphereAtmosphere Transfer Scheme (BATS, Dickinson et al., 1993) and from the results of the simulation with the Community Climate Model (CCM2) (http://www.cgd.ucar.edu/cms/ccm.html) coupled with BATS (http://www.atmo.arizona.edu/faculty/research/bats/batsmain.html) performed by Bonan (1994). For instance, in BATS, the active soil layer is 1-m deep for 11 of the 16 land-cover types, and 1.5-2-m deep for the other types. The soil sublayer is 9-m deep for all land-cover types. Here these two layers are assumed to be $1 \mathrm{~m}$ and $10 \mathrm{~m}$ deep, respectively. The ratio of evaporation to precipitation $\left(r_{E P}\right)$ in the CCM2-BATS simulation is 0.60 (Both evaporation and precipitation are spatially and temporally averaged before taking the ratio).The corresponding land-surface sensible and latent heat fluxes in the CCM2-BATS simulation are about 33 and $61 \mathrm{Wm}^{-2}$, respectively. Based on these values of the fluxes, as well as climatological values of $T_{a}, T_{g}, q_{a}$, and $\eta$ provided in Table 1 , one can obtain $H_{0}$ and $E_{0}$ from Eqs. 7-8, respectively.

Table 1 Parameters used in the continental water and energy cycle system (from Liu and Avissar 1999b)

\begin{tabular}{|c|c|c|c|c|}
\hline \multicolumn{2}{|c|}{ Parameter Meaning } & Unit & \multicolumn{2}{|c|}{ Mean Range in FAST* } \\
\hline $\mathrm{T}_{\mathrm{a}}$ & Air temperature & $\mathrm{K}$ & 255.0 & $250.0-260.0$ \\
\hline $\mathrm{q}_{\mathrm{a}}$ & Air specific humidity & $\mathrm{g} / \mathrm{kg}$ & 5.0 & $3.0-7.0$ \\
\hline $\mathrm{T}_{\mathrm{g}}$ & Soil temperature & K & 285.0 & $280.0-290.0$ \\
\hline $\mathrm{W}_{\mathrm{g}}$ & Soil volumetric water content & $\%$ & 250.0 & $10.0-40.0$ \\
\hline $\mathrm{S}_{0}$ & Solar radiation at tropopause & $\mathrm{Wm}^{-2}$ & 330.0 & - \\
\hline$r_{\mathrm{EP}}$ & Ratio of evaporation to precipitation & $\%$ & 60.0 & $45.0-75.0$ \\
\hline $\mathrm{n}$ & Cloud fraction & $\%$ & 50.0 & $35.0-65.0$ \\
\hline $\mathrm{d}_{\mathrm{T}}$ & Depth of thermally active soil layer & $\mathrm{m}$ & 10.0 & 7.5-12.5 \\
\hline $\mathrm{d}_{\mathrm{T} 0}$ & Depth of thermal soil sublayer & $\mathrm{m}$ & 10.0 & — \\
\hline $\mathrm{d}_{\mathrm{w}}$ & Depth of hydrologically active soil layer & $\mathrm{m}$ & 1.0 & $0.75-1.25$ \\
\hline $\mathrm{d}_{\mathrm{w} 0}$ & Depth of hydrological sublayer & $\mathrm{m}$ & 10.0 & - \\
\hline$h_{a}$ & Height of air column & $\mathrm{km}$ & 10.0 & $9.0-11.0$ \\
\hline $\mathrm{D}_{\mathrm{T}}$ & Soil thermal diffusivity & $10^{-7} \mathrm{~m}^{2} \mathrm{~s}^{-1}$ & 5.0 & $2.5-7.5$ \\
\hline$D_{W}$ & Soil hydraulic diffusivity & $10^{-8} \mathrm{~m}^{2} \mathrm{~s}^{-1}$ & 5.0 & $2.5-7.5$ \\
\hline $\mathrm{C}_{\mathrm{g}}$ & Soil heat capacity & $\mathrm{JK}^{-1} \mathrm{~m}^{-3}$ & 1.0 & $0.75-1.25$ \\
\hline $\mathrm{W}_{\mathrm{s}}$ & Saturated soil volumetric water content & $\%$ & 40.0 & $30.0-50.0$ \\
\hline $\mathrm{H}_{0}$ & Turbulent sensible-heat exchange index & $\mathrm{Wm}^{-2} \mathrm{~K}^{-1}$ & 1.0 & $0.5-1.5$ \\
\hline $\mathrm{E}_{0}$ & Turbulent water vapor exchange index & $10^{-3} \mathrm{kgm}^{-2} \mathrm{~s}^{-1}$ & 14.5 & 3.5-5.5 \\
\hline$\rho_{\mathrm{a}}$ & Air density & $\mathrm{kgm}^{-3}$ & 0.75 & - \\
\hline
\end{tabular}

*FAST stands for Fourier amplitude sensitivity test, see Section 4.

Table 2 Damping times of the fourth-, third-, and second order models (in days) (from Liu and Avissar 1999b) 


\begin{tabular}{|l|l|rrrr|}
\hline $\begin{array}{l}\text { Model } \\
\text { Order }\end{array}$ & \multicolumn{1}{|c|}{ Variables } & \multicolumn{4}{|c|}{ Scales } \\
\hline 4th & $\mathrm{T}_{\mathrm{a}}, \mathrm{q}_{\mathrm{a}}, \mathrm{T}_{\mathrm{g}}, \mathrm{W}_{\mathrm{g}}$ & 231.5 & 57.5 & 5.7 & \multicolumn{1}{c|}{4.2} \\
\hline 3rd & $\mathrm{q}_{\mathrm{a}}, \mathrm{T}_{\mathrm{g}}, \mathrm{W}_{\mathrm{g}}$ & 229.4 & 7.7 & 1.2 & \\
& $\mathrm{~T}_{\mathrm{a}}, \mathrm{T}_{\mathrm{g}}, \mathrm{W}_{\mathrm{g}}$ & 195.6 & 18.7 & 1.3 & \\
& $\mathrm{~T}_{\mathrm{a}}, \mathrm{q}_{\mathrm{a}}, \mathrm{W}_{\mathrm{g}}$ & 235.6 & 29.1 & 5.8 & \\
& $\mathrm{~T}_{\mathrm{a}}, \mathrm{q}_{\mathrm{a}}, \mathrm{T}_{\mathrm{g}}$ & 58.1 & 5.7 & 1.2 & \\
\hline 2nd & $\mathrm{T}_{\mathrm{a}}, \mathrm{q}_{\mathrm{a}}$ & 29.6 & 5.9 & & \\
& $\mathrm{~T}_{\mathrm{g}}, \mathrm{W}_{\mathrm{g}}$ & 188.2 & 1.3 & & \\
& $\mathrm{~T}_{\mathrm{a}}, \mathrm{T}_{\mathrm{g}}$ & 18.7 & 1.3 & & \\
& $\mathrm{q}_{\mathrm{a}}, \mathrm{W}_{\mathrm{g}}$ & 233.0 & 6.6 & & \\
\hline
\end{tabular}

Eq.13 has four solutions. The number of solutions is reduced to three and two for the third- and second-order models, respectively. The solutions, given in Table 2, measure damping times or scales. Note that each solution (scale) represents a perturbation mode of the system, rather than a time scale of a variable. The damping times with the fourth-order model are of the orders of one day, one week, two months, and eight months. Thus, hereafter, they will be referred to as daily-, weekly-, monthly-, and seasonal-scale processes, respectively. The monthly and seasonal scales, which represent long-term variations, will be referred to as long-term scales. The damping time points out how fast disturbances decay with time. Consequently, it provides an essential information for understanding at which climatic scale a particular perturbation in the water cycle persists. A damping time of a few days implies that the considered perturbation is relevant to short-term, synoptic-scale processes, but is unlikely to have a significant impact on longer time scales. On the other hand, a damping time of several months suggests a potential impact on seasonal climatic processes.

\section{Control of Seasonal Scale by Water Exchange}

a. Relative importance of model parameters

The Fourier Amplitude Sensitivity Test (FAST) was used to identify which parameters mostly affect the damping times obtained from this fourth-order continental water and energy cycle model. A complete description of the theory and implementation of FAST and approximations used in computer implementation, mainly following Cukier et al. (1973), was given in Collins and Avissar (1994).

The number of parameters in the FAST computer program used in this analysis is limited to 15. The chosen parameters from the fourth-order model are listed in Table 1. Among the parameters which are included in the FAST analysis, the role of solar radiation in the damping times can not be directly examined by the sensitivity analysis because the latent and sensible heat fluxes have been prescribed separately, without any constraint on the balance between the surface net radiation and the two fluxes (the role of solar radiation will 
be discussed below using a regular sensitivity analysis technique); $d_{T 0}$ and $d_{w 0}$ have similar roles to $d_{T}$ and $d_{w}$; and $\rho_{a}$ has a similar role to $h_{a}$. Normal distributions of the 15 input parameters were considered, and their ranges are also given in that table. Figure 2 depicts the partial variance of the damping times, which shows the sensitivity of model output parameters to the variation of individual input parameters in terms of a percentage of the variance. It appears that the longest damping time scale, which is about 9.5 months, is very sensitive to soil moisture, ratio of evaporation to precipitation, soil temperature, and soil moisture at saturation. Each of these parameters contributes more than $10 \%$ to the total variance. In addition, drag coefficient of water vapor flux, depth of hydrologically active soil layer, air humidity, and soil hydraulic diffusivity have some impact on the variance. It is interesting to note that all these parameters are related to soil hydrological processes. Indeed, the ratio of $W_{g}$ to $W_{s}$ affects the actual evaporation, $E_{0}, T_{g}$, and $q_{a}$ affect the potential evaporation, $r_{E P}$ is related to evaporation and precipitation, and $D_{w}$ and $d_{w}$ affect the transfer of water between the active soil layer and the soil sublayer. Thus, clearly, the parameters associated with soil hydrology determine the length of the longest process in the water cycle.

\section{b. Sensitivity to model parameters}

Based on the FAST analysis, the effects of a number of the most important parameters on the seasonal damping time scale are examined using a regular sensitivity technique, that is, analyzing a perturbation in the time scale due to a change in a parameter . These parameters can significantly modify the magnitude of the damping time scale. For instance, an increase of $E_{o}$ (which is proportional to the turbulence activity in the atmospheric surface layer) from 3.5 to $5.5 \times 10^{-3} \mathrm{kgm}^{-2} \mathrm{~s}^{-1}$, results in a reduction of the damping time from 283 to 196 days. When $r_{E P}$ and $W_{s}$ increase, they result in a very significant increase of the damping time. A dry soil $\left(W_{g}=0.1\right)$ has a damping time of 485 days, but a wet soil $\left(W_{g}=0.4\right)$ has a damping time of only 153 days, emphasizing that a moist soil damps a perturbation much faster than a dry soil does.

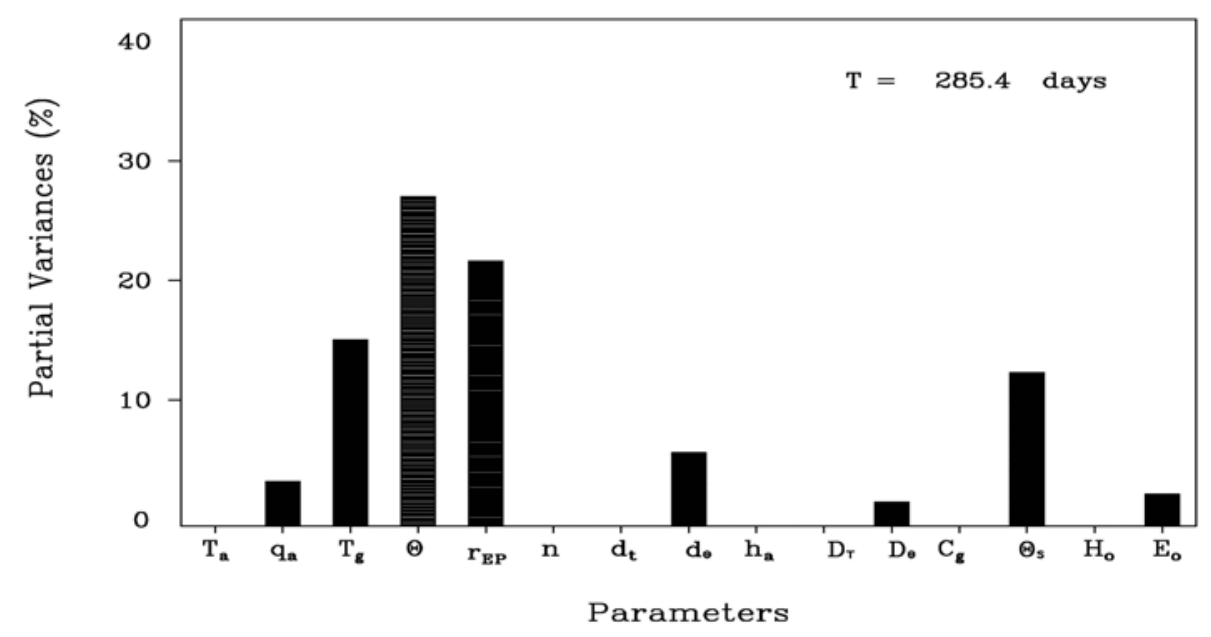


Figure 2 FAST analysis of the fourth-order model outputs for the seasonal scale indicated by the average damping time T obtained from all model runs. Partial variances reflect sensitivity of the damping times to the model inputs (from Liu and Avissar 1999b).

The evaporation equation (Eq.8) consists of two variables, namely potential evaporation, $E_{p}$, and a fraction factor, $\eta \cdot E_{p}$ increases with $T_{g}$ and $E_{o}$, and decreases with increasing $q_{a}$. Therefore, it can be derived from the relations between these three parameters and the damping time that the damping time scale decreases with increase in potential evaporation. The relations between the damping time and $W_{g}$ and $W_{s}$ indicate that the damping time decreases with increasing $\eta$. The combined effects of $E_{p}$ and $\eta$ result in decrease of the damping time with increase in actual evaporation.

The runoff parameterization (Eq.10) consists of two variables as well, i.e., $\eta$, and the difference between precipitation and actual evaporation $(P-E)$. The latter term is inversely proportional to $r_{E P}$. Figure 3 shows that the damping time increases from 138 to 393 days with variation of $r_{E P}$ from 0.45 to 0.75 or, equivalently, decreases with $(P-E)$. Therefore, together with the variation of $\eta$, the damping time decreases with increase in runoff.

The last term in the right-hand side of Eq. 4 is the exchange of soil moisture between the active layer and the sublayer, which acts as a force-restore term for soil moisture disturbances. Its intensity is proportional to $D_{w}$, and inversely proportional to $d_{w}$. The damping time decreases with increasing $D_{w}$, and increases with $d_{w}$ (not shown). Therefore, it decreases with a faster exchange between the two soil layers. $d_{w}$ is also a measure of the total available water in the active layer. For a given forcing, as expressed by the right-hand side terms in Eq. 3, the larger $d_{w}$, the slower the variation rate of soil moisture, and the longer the damping time. This effect is somewhat similar to that of soil heat capacity in damping the variation of soil temperature. However, evaporation and runoff affect the damping time much more significantly than the exchange between the two soil layers does.

The above results indicate that the smaller the fluxes of water in the continental water and energy cycle system (i.e., evaporation, runoff, and underground diffusion), the longer the damping time is, and, therefore, the more significant persistence is.

By using the Bowen ratio to relate sensible to latent heat flux, the role of solar radiation in the seasonal scale can be examined. From such an analysis, it appears that the damping time decreases from 295 to 206 days as solar radiation increases from 300 to $380 \mathrm{Wm}^{-2}$.

\section{Understanding Global Water Cycle using Analytical Models}

\subsection{Time scales of water cycle}

The time scale relevant to this analysis is the period spanned by an anomalous hydrological process. For non-oscillation variability, it is the time period during which anomalies maintain the same sign, and for oscillation variability, it is the half-time period of 
the oscillations. This analysis aims to identify the major scales at which land-surface processes can contribute to water cycle variability.

\section{a. Interpretation of solutions in terms of time scales}

The solutions of the analytical models measure time scales of variability in the water and energy cycle system. This can be illustrated by the first-order model of soil water balance equation (Delworth and Manabe 1988):

$$
d w(t) / d t=P-E-F,
$$

where $w=M_{g} W_{g} . P$ is an external forcing and $F$ is related to $P$. $E$ can be calculated by

$$
E=\lambda w(t)
$$

where $\lambda=E_{p} / W_{s}$. Considering the perturbation form of Eq.16 and assuming no perturbations in precipitation and runoff , the solution is:

$$
w(t)=w(t=0) e^{-\lambda t}
$$

indicating that initial soil moisture perturbation damps exponentially with a rate of $\lambda$. The reciprocal of the rate is the e-folding time $=1 / \lambda=W_{s} / E_{p}$. This time is used to measure time scale of soil moisture variability.

\section{b. Scale}

Delworth and Manabe (1988) obtained a globally averaged scale of soil moisture variability of about one to two months based on the simulations with the Geophysical Fluid Dynamics Laboratory (GFDL) GCM. A value of three months was obtained based on the soil moisture measurements in Russia (Vinnikov et al., 1996) and about two and half months based on the soil moisture measurements in North China (Entin et al., 2000).

Perturbation strength, defined as the time period over which a perturbation maintains the same sign as an initial anomaly, is presented in Figure 3. It is calculated using a 10-year CCM2-BATS simulation conducted by Bonan (1994) and it ranges between about two to eight months (Liu and Avissar,1999a). 

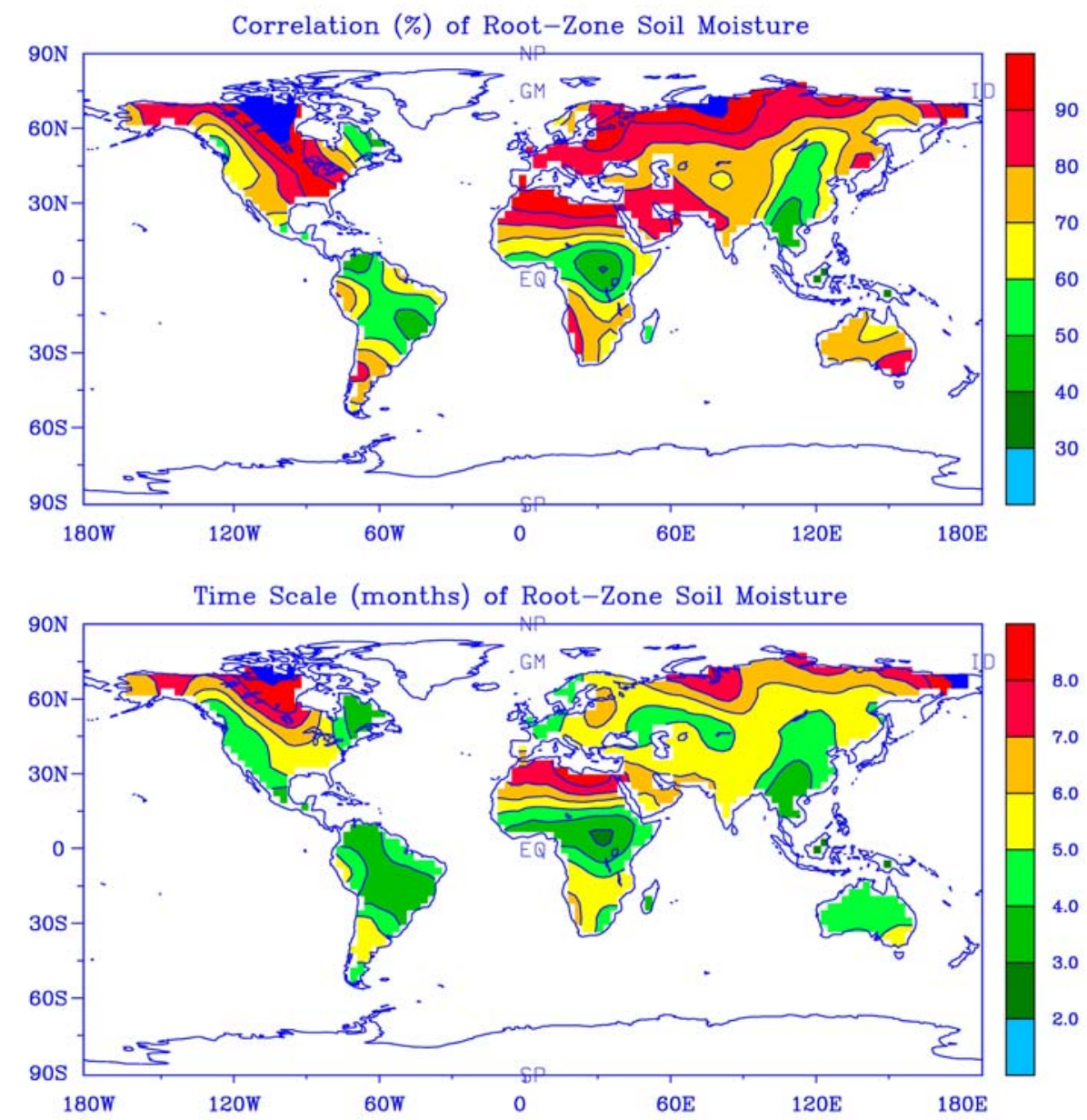

Figure 3 One-month lag autocorrelation coefficients (top) and perturbation time scales (bottom) of the root-layer soil moisture simulated with CCM2-BATS (from Liu and Avissar, 1999a).

These studies suggest that the major scales at which land surface processes could affect the long-term atmospheric water cycle variability are the monthly and seasonal scales. Global climate models have provided some numerical evidence for these analytical results (e.g., Yeh et al., 1984; Liu and Avissar 1999a). Yeh et al (1984) conducted a numerical experiment of initial soil moisture forcing with a simplified version of the GFDL GCM, and showed that the induced anomalies in evaporation, precipitation, and soil moisture last for three to five months.

\section{c. Time scales in different-order models}

Interactions between soil moisture and other variables included in some higher-order models could significantly increase the length of a scale, as indicated by the time scales obtained from the four solutions of Eq.17. A seasonal scale as long as eight months is obtained (Table 2). 
The damping times in the four third-order systems (Table 2) indicate that the seasonal damping time scale appears only in the third-order systems with disturbance of soil moisture. The longest damping time in the first three systems varies between 196 and 236 days. This emphasizes that the soil moisture feedback, and its interactions with the other variables, are the primary cause for the damping time scale. In the third-order system without physical processes related to soil moisture disturbances, the maximum damping time scale is only of the order of two months. In addition, among the various interactions, the one between soil moisture and air humidity is the predominant: Excluding this interaction results in a reduction of the damping time from 232 to 196 days. On the other hand, the exclusion of the interactions involving air and soil temperature has little impact on the damping time scales.

Four second-order systems are considered in Table 2. With System (i), which does not account for soil-variable perturbations, the disturbances sustain for a period of about one month. However, a damping time of about six months is obtained with System (ii), which does not account for air-variable perturbations. Considering these results and those obtained with the third-order systems, it seems that atmospheric disturbances can persist on the seasonal scale only if there are interactions between atmospheric variables and soil moisture. The other two second-order systems further illustrate the importance of the moisture processes. Clearly, thermal disturbances have a short-time impact on the water cycle, while moisture disturbances persist for as long as eight months.

Each of the four first-order models contains only one of the four perturbation variables. Obviously, in these cases, the variation of the disturbances in the systems is caused by selffeedback. The results show that the damping time is about three and a half months for the first-order system that accounts for soil moisture perturbations, and several days to three weeks for the other systems.

It is concluded from the above results that self-feedbacks are the primary factors affecting the time scale of perturbation. Specifically, soil moisture feedback causes the seasonal-scale perturbation. The interactions between soil moisture and the other variables of the water and energy cycle system (mainly air humidity), cause a significant increase of the seasonal time scale. For atmospheric disturbances to persist at the seasonal scale, interactions between the atmosphere and soil moisture must be considered

\subsection{Persistence of water cycle}

It has long been recognized that precipitation can persist over relatively long time periods (i.e., months to seasons), a feature known as persistence of atmospheric disturbances. This property indicates that if an anomaly occurs in a month or season, then there is a good chance for this anomaly to occur in the following month or season as well. Therefore, this property is quite useful for the predictability of the system. Using autocorrelations between adjacent monthly or seasonal rainfall and other atmospheric variables, many studies (e.g., Namias, 1952) demonstrated the existence of such persistence. 
Land can contribute to precipitation persistence through its long memory and interaction with the atmosphere. For example, following a dry spring, soil would likely be desiccated during the summer. This would result in a relatively large sensible heat flux injected in the atmosphere from the ground surface, which could perhaps maintain anticyclonic circulations. Under such circumstances, one could expect reduced summer rainfall. A theoretical framework of the role of soil moisture memory in precipitation statistics was presented by Koster et al. (2000), which indicates that a larger soil moisture memory would lead to a larger correlation between initial precipitation and its subsequent variability.

\section{a. Interpretation of model solutions in terms of persistence}

The solutions of the analytical models also measure persistence of anomalies in the water and energy cycle system. Persistence can be estimated using autocorrelation of a variable. For soil moisture, persistence can be related to its time scale by (Delworth and Manabe, 1988)

$$
r(\tau)=e^{-\lambda \tau}
$$

where $r$ and $\tau$ are autocorrelation and time lag, respectively. This relation indicates that the larger the time scale is, the more significant the persistence of soil moisture anomalies is.

\section{b. Persistence signals}

Persistence of the land-atmosphere system has been investigated with simulated data series. Using multi-year simulations produced with the GFDL GCM, Delworth and Manabe (1988) analyzed the variability in soil moisture and found statistically significant persistence of soil moisture. Liu and Avissar (1999a) obtained similar results from an analysis based on a simulation with the CCM2-BATS, as shown in Figure 3. The one-month lag autocorrelation coefficients of soil moisture vary between about $30 \%$ and $90 \%$, with a global average of $61 \%$. Correlations are statistically significant at a 99.9\% confidence level (critical value of 29.6\%) almost everywhere. This emphasizes a strong persistence of the simulated soil moisture.

\section{c. Control of persistence by water exchange}

The solution of the first-order model (Eq.16), $\lambda$, is determined by potential evaporation, with a fixed water field capacity. A larger potential evaporation leads to a faster decay rate and thus a less significant persistence of soil moisture disturbances. Because potential evaporation is larger at low latitudes and in warm seasons, persistence of soil moisture is more significant at high latitudes and in winter (Delworth and Manabe, 1988). In Figure 4, autocorrelation coefficients tend to increase from about $30 \%$ in the equatorial regions to $80-90 \%$ at high latitudes.

Persistence also depends on climate regime: it is stronger in drier geographic regions (Liu and Avissar, 1999a). For soil moisture, the coefficients are less than 55\% in the moist 
Southeast China, and over $80 \%$ in the dry Northwest China. Persistence of the other three variables (soil temperature, air humidity and temperature) has the same dependence on climate regime as soil moisture. In addition, a global analysis (Liu and Avissar, 1999a) depicts relatively large autocorrelation coefficients in dry northern Africa and a strong contrast between this region and the moist tropics, where autocorrelation coefficients are relatively low.

\section{3 Physical Mechanisms}

\section{a. Feedbacks}

The evolution of the disturbances in the fourth-order continental water and energy cycle system is controlled by two mechanisms: self-feedbacks, which are measured by the four diagonal elements in the matrix $C$ (Eq. 11, Table 3), and interactions, which are measured by the 12 other elements of this matrix. All the four diagonal elements are negative. Thus, the average of the roots, which is equal to the average of the four diagonal elements of the matrix $C$, is also negative. A negative value indicates a negative self-feedback, which results in disturbance decay.

Table 3 Values of matrix $C=\left(c_{i j}\right)\left(\times 10^{-6}\right)($ from Liu and Avissar 1999b)

\begin{tabular}{|l|cccl|}
\hline & $j=1$ & $j=2$ & $j=3$ & $j=4$ \\
\hline$i=1$ & -0.641 & 0.007 & 0.1171 & 0.0 \\
$i=2$ & 4.494 & -1.708 & 19.79 & 0.6672 \\
$i=3$ & 1.673 & 0.0456 & -9.178 & -0.2195 \\
$i=4$ & -0.264 & 0.9961 & -1.113 & -0.0883 \\
\hline
\end{tabular}

A physical explanation to the roles of these self-feedbacks can be given by using the perturbation equation (Eq.11). For instance, a positive perturbation of air temperature results in a decrease of the sensible heat released in the atmospheric surface layer from the land surface, and in an increase of the heat lost by long-wave radiation. In addition, one can expect a decrease in precipitation, which results in a reduced release of condensation latent heat, due to the corresponding lower relative humidity. These effects induce a negative air temperature tendency. Similarly, a positive perturbation of soil temperature results in an increase in heat loss to the atmosphere by sensible heat flux, latent heat flux, and long-wave radiation, and into the soil sublayer by conduction, which leads to a decrease in soil temperature. A positive perturbation of air moisture results in a decrease of the amount of water evaporated from the land surface and, possibly, in an increase in condensation, which removes vapor from the atmosphere. Finally, a positive perturbation of soil moisture results in an increase in evaporation to the atmosphere, in runoff, and in the amount of water lost by percolation to the soil sublayer. 


\section{b. Interactions}

There are also positive interactions in the system, as indicated by the positive elements of the matrix $C$, which can promote the growth of disturbances. For example, a positive perturbation of soil moisture results in a more humid atmosphere due to a stronger evaporation at the land surface, and a moister atmosphere is likely to produce more precipitation, which in turn increases soil moisture.

The overall evolution of the disturbances (i.e., amplification or decay with time) depends on the relative importance of the feedbacks and the interactions. Because all the roots of the water and energy cycle system (and their mean) are negative (Table 3), disturbances decay with time. Thus, one can expect that self-feedbacks have a predominant impact on this system.

In the fourth-order model developed by Brubaker and Entekhabi (1996), self-feedbacks of soil moisture (through control of infiltration and evaporation) and temperature (through dependence of surface specific humidity) serve to restore each state individually, and interactions between soil moisture and temperature (through soil moisture control of evaporation and the temperature dependence on surface specific humidity) act to reinforce anomaly of the other state.

\section{c. External forcing}

The soil water balance equation with the precipitation expressed by Eq.15 (RodriguezIturbe et al., 1991) allows us to study variation in soil moisture in response to atmospheric forcing and feedback. The forcing was found to lead to transitions from one stable mode of soil moisture to another. Figure 4 shows soil moisture under different intensities of atmospheric forcing indicated by $\sigma^{2}$. For weak forcing (panel a), there is a steady state with a soil moisture most probably occurring at 0.5 . This is the value of an equilibrium solution of the water balance equation without atmospheric forcing (that is, $\sigma^{2}=0$ ). For moderate forcing (panel b) and strong forcing (panel c), the system has a quite different property. Two states of soil moisture are obtained with the most probable values of 0.2 and 0.8 . The soil frequently experiences persistent dry and wet anomalies. Atmospheric forcing may lead to transitions from one to another state. 

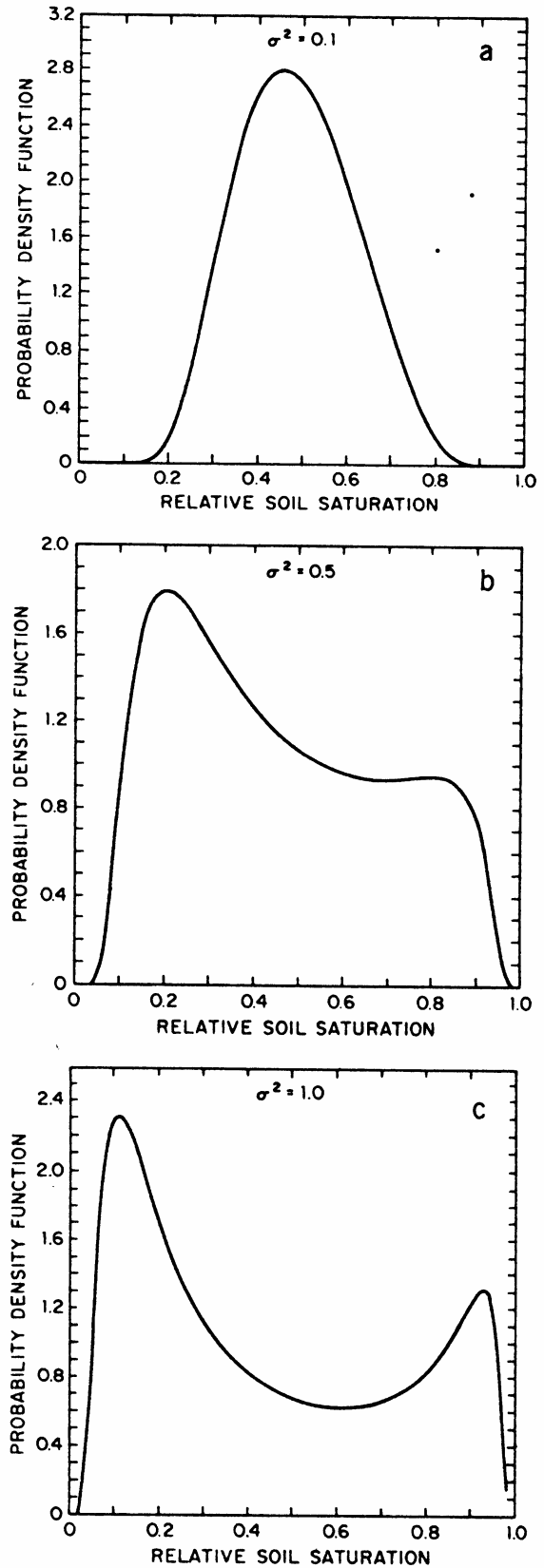

Figure 4. Steady state probability density functions of soil moisture under different atmospheric forcing (After Rodriguez-Iturbe et al., 1991).

\section{Summary and Discussion}

Analytical models for examining continental water cycle have been described and applied to studies of time scale, persistence, and physical mechanism of the water cycle 
variability. A fourth-order model of land-atmosphere energy and water balance was used as an example to show the procedure for obtaining the perturbation equation, its solutions, the impacts of the system properties, and the physical interpretation.

The analytical results indicated that the fourth-order model has seasonal, monthly, weekly, and daily damping time scales. The seasonal scale appears only in those third- or secondorder models that include disturbance of soil moisture. This emphasizes that the soil moisture feedback, and its interactions with the other variables, are the primary cause for the scale. In the model without soil moisture disturbance, the maximum time scale is only about two months. In addition, among the various interactions, the one between soil moisture and air humidity is the predominant: excluding this interaction results in a reduction in the length of the seasonal scale by more than one month.

Perturbations in the land-atmosphere system could persist for seasons. Thus, persistence is an inherent property of the continental water and energy cycle. This result provides theoretical support to the studies of Namias (1952) and others, who indicated that atmospheric anomalies possess monthly-to-seasonal persistence. The time scale and persistence features were also obtained in a number of numerical simulation and observation studies (e.g., Walker and Rowntree 1977, Rind 1982, Rowntree and Bolton 1983, Yeh et al. 1984, Walsh et al. 1985, Liu et al. 1993, Gao et al. 1996, Vinnikov et al. 1996). In a study using the National Center for Atmospheric Research (NCAR) Community Climate Model (CCM2) coupled with the Biosphere-Atmosphere Transfer Schemes (BATS) and observations of soil and atmospheric variables in China, Liu and Avissar (1999a) showed that soil moisture variability has significant persistence, with time scales on the order of months to seasons.

The seasonal damping time scale is mostly affected by the physical factors related to soil moisture (i.e., evaporation, runoff, and soil-moisture diffusion), and the monthly damping time scale is mainly affected by the thermal characteristics of the system. The soilmoisture self-feedback is a primary cause for the seasonal damping time scale, and interactions between soil moisture and the other variables of the system greatly increase length of the damping time scale. These results clearly emphasize the importance of soil moisture in the variability and the causes of water cycle at seasonal time scale and support findings from other investigations with more complex tools. For instance, Castelli and Rodriguez-Iturbe (1995) found that land-atmosphere interactions can influence local atmospheric processes through the modification of the vertical lapse rate, and large-scale processes through the global dynamics of baroclinic waves. The advection rates of mass and energy, and the strength of the ageostrophic frontal circulations are particularly important in that case. Betts et al.(1996) showed that the monthly precipitation pattern is quite sensitive to initial soil moisture in the FIFE and BOREAS experiments. They suggested that, due to the memory of the soil-moisture reservoir, some predictability exists at monthly and seasonal scales. Avissar (1995) emphasized the importance of an appropriate representation of soil moisture's role to global climate model. While the analytical models described in this article are able to provide significant insights on the continental water cycle, it is important to keep 
in mind that only small-amplitude disturbances in a linear system were considered here. One obvious limitation with such models is that they neglect scale interactions in the climate system. In the real world, short-time forcings can generate long-time fluctuations. The relations between the tropical convection activities, the 30-60 day low-frequency fluctuation, and the El Nino/Southern Oscillation are examples of such interactions.

The time scale of the land-atmosphere system obtained by the linear forth-order model is independent on the sign of the initial perturbation in soil moisture. Actual processes in the land-atmosphere system are nonlinear. For example, evapotranspiration, which is a major parameter for the seasonal time scale, is specified to be linearly proportional to soil moisture in the forth-order model. In other words, the increasing rate of evapotranspiration with soil moisture is constant. But evapotranspiration actually increases nonlinearly with soil moisture (Lowry, 1959): the increasing rate is smaller when the soil is dry and larger when the soil is wet for the bare soil. This suggests that the seasonal time scale or persistence time period of the land-atmosphere system should be different when the soil is abnormally dry and wet.

The fourth-order analytical model described here does not have positive growth modes. Two factors contribute to this. First, the model does not have external forcing related to, for example, atmospheric dynamics, which causes disturbances in the water cycle. Second, the nature of development of the system (i.e., growth or decay) depends very much on model parameters. In this study, climatological values have been given to these parameters. Thus, results presented here reflect the climatological behavior of the water cycle. However, the model could give solutions which indicate growing disturbances by selecting specific sets of parameters reflecting local, short-term conditions.

Another limitation with the analytical models is that it is unable to examine the interaction between the seasonal cycle and the processes involved in the models. For example, many parameters used in the fourth-order model of LA99 have significant seasonal cycle. Among those which are important to the seasonal time scale and persistence, soil moisture, soil temperature (therefore, potential evaporation), and solar radiation are much smaller in winter than in summer. This suggests that the damping time of the seasonal scale should be longer in winter. In other words, perturbation in the land-atmosphere system described by the fourth-order system should last longer in winter. This feature was found in the analysis of a 3-D climate modeling study (Delworth and Manabe, 1988) but cannot be showed with this analytical model in which the model parameters are annual averages.

Snowpack and vegetation are two other primary processes involved in the water cycle. Snow can significantly affect soil moisture and, therefore, affect persistence of the water cycle. Vegetation can influence long-term water cycle variability by modifying surface albedo, intercepting precipitation, extracting soil water from deep layers through transpiration, and resisting runoff. Vegetation dynamics have a significant influence on the seasonal and interannual water cycle (e.g., Dickinson et al., 1998; Lu et al., 1999). Thus, 
snow and vegetation processes, in addition to soil moisture, need to be included in analytical models to better understand seasonal and interannual variability of the water cycle.

\section{Software links}

\section{NCAR CCM2}

The National Center for Atmospheric Research Community Climate Model version 2. It is used to perform simulation of global climate. (http://www.cgd.ucar.edu/cms/ccm.html)

\section{BATS}

The Biosphere-Atmosphere Transfer Scheme. It is used to simulate land-surface processes. (http://www.atmo.arizona.edu/faculty/research/bats/batsmain.html)

\section{References}

Avissar, R., and M.M. Verstraete (1990). The representation of continental surface processes in atmospheric models. Rev. Geophys., 28, 35-52.

Avissar, R. (1995). Recent Advances in the representation of land-atmosphere interactions in global climate models. Rev. Geophys., 33, 1005-1010.

Avissar, R., and Y.-Q. Liu (1996). A three-dimensional numerical study of shallow convective clouds and precipitation induced by land-surface forcings. J. Geophys. Res., 101, 7499-7518.

Betts, A.K., J.H. Ball, A.C.M. Beljaars, M.J. Miller, and P.A. Viterbo (1996). The landsurface atmosphere interaction: A review based on observational and global modeling perspectives. J. Geophys. Res., 101, 7209-7226.

Bonan, G.B. (1994). Comparison of the land surface climatology of the NCAR CCM2 at R15 and T42 resolutions with implications for sub-grid land surface heterogeneity. $J$. Geophys. Res., 99, 10357-10364.

Brubaker, K.L., and D. Entekhabi (1996). Analysis of feedback mechanisms in landatmospheric interaction. Water Resources Res., 32, 134301357.

Cane, M.A. (1992). Tropical Pacific ENSO models: ENSO as a mode of the coupled system. in "Climate System Modeling" (Ed. K.E. Trenberth), The Press of the Uni. Of Cambridge, 788pp.

Castelli, F., and I. Rodriguez-Iturbe (1995). Soil moisture-atmosphere interaction in a moist semigeostrophic model of baroclinic instability, J. Atmos. Sci., 52, 2152-2159.

Collins, C. and R. Avissar (1994). An evaluation with the Fourier Amplitude Sensitivity Test (FAST) of which land surface parameters are of greatest importance in atmospheric modeling. J. Clim., 7, 681-703.

Cukier, R.I., C.M. Fortuin, K.E. Shuler, A.G. Petschek, and J.H. Schaibly (1973). Study of the sensitivity of coupled reaction systems to uncertainties in rate coefficients. I. Theory. J. Chem. Phys., 59, 3873-3878.

Delworth, T. and S. Manabe (1988). The influence of potential evaporation on the variabilities of simulated soil wetness and climate. J. Clim., 1, 523-547. 
Delworth, T. and S. Manabe (1989). The influence of soil wetness on near-surface atmospheric variability. J. Clim., 2, 1447-1462.

Dickinson, R. E., A. Henderson-Sellers, and P.J.Kennedy (1993). Biosphere-Atmosphere Transfer Scheme (BATS) Version $1 E$ as Coupled to the NCAR Community Climate Model. NCAR Tech. Note/TN-387, National Center for Atmospheric Research, Boulder, CO., 72pp.

Dickinson, R. E., M. Shaikh, R. Bryant, and L. Graumlich (1998). Interactive canopies for a climate model. J. Clim., 11, 2823-2836.

Dirmeyer, P.A. (2003). The role of the land surface background state in climate predictability. J. Hydrometeor., 4, 599-610.

Eltahir, E.A.B. (1998). A soil moisture-rainfall feedback mechanism. 1. Theory and observations. Water Resour. Res., 34, 765-785.

Entekhabi, D., I. Rodriguez-Iturbe, and R.I. Bras (1992). Variability in large-scale water balance with land surface-atmosphere interaction. J. Clim., 57, 798-813.

Entin, J. K., A. Robock, K. Y. Vinnikov, S. E. Hollinger, S.X. Liu, and A. Namkai (2000). Temporal and spatial scales of observed soil moisture variations in the extratropics. $J$. Geophys. Res., 105, 11,865-11,877.

Findell, K.L., and E.A.B. Eltahir (2003). Atmospheric controls on soil moisture-boundary layer interactions. Part I: Framework development. J. Hydrometeorol., 4, 552-569.

Gao, X. G., S. Sorooshian, and H. V. Gupta (1996). A sensitivity analysis of the BiosphereAtmosphere Transfer Scheme (BATS), J. Geophys. Res., 101(D3), 7279-7290.

Giorgi, F., L.O. Means, C. Shields, and L. Mayer (1996). A regional model study of the importance of local versus remote controls of the 1988 drought and the 1993 flood over the Central United States. J. Clim., 9, 1150-1162.

Holton, J.R. (1979). An Introduction to Dynamic Meteorology. Academic Press, 391pp.

Huang, J., H.M. van den Dool, and K.P Georgakakos (1996). Analysis of model calculated soil moisture over the United States (1931-1993) and applications to long-range temperature forecasts. J. Clim., 9, 1350-1362.

Koster, R.D. and M.J. Suarez (1995). Relative contributions of land and ocean processes to precipitation variability. J. Geophys. Res-Atoms., 100 (D7), 13775-13790.

Koster, R.D., M.J. Suarez, and M. Heiser (2000). Variance and predictability of precipitation at seasonal-to-interannual timescales on precipitation. J. Hydrometeor., 1, 26-46.

Liu, Y.-Q., D.Z. Ye, and J.J. Ji (1992). Influence of soil moisture and vegetation on climate. I: A theoretical analysis on persistence of short-term climatic anomalies. Science in China, 35, 441-448.

Liu, Y.-Q., D.Z. Ye, and J.J. Jin (1993). Influence of soil moisture and vegetation on climate. II: numerical experiments on persistence of short term climatic anomalies, Science in China, 36, 102-109.

Liu, Y.-Q., and R. Avissar (1999a). A study of persistence in the land-atmosphere system using a general circulation model and conservations. J. Clim., 12, 2139-2153.

Liu, Y.-Q., and R. Avissar (1999b). A study of persistence in the land-atmosphere system with a fourth-order analytical model. J. Clim., 12, 2154-2168. 
Lowry, W.P. (1959). The falling rate phase of evaporative soil moisture loss: A critical evaluation, Bull. Am. Meteorol. Soc., 40, 605.

Lu, L., R.A. Pielke, G.E. Liston, W.J. Parton, D. Ojima, and M. Hartman (2001). Implementation of a two-way interactive atmospheric and ecological model and its application to the central United States. J. Clim., 13, 900-919.

Mintz, Y. (1984). The sensitivity of numerically simulated climate to land-surface boundary conditions. The Global Climate, Houghton, J. T., Ed., Cambridge University Press, 79105.

Namias, J. (1952). The annual course of month-to-month persistence in climatic anomalies. Bull. Amer. Meteor. Soc., 33, 279-285.

Paltridge, G.W. (1974). Global cloud cover and earth surface temperature. J. Atmos. Sci., 31, 1571-1576.

Rind, D. (1982). The influence of ground moisture conditions in North America on summer climate as modeled in the GISS GCM, Mon. Wea. Rev., 110, 1487-1494.

Rodriguez-Iturbe, I., D. Entekhabi, and R.I. Bras (1991). Nonlinear dynamics of soil moisture at climate scales: I. Stochastic analysis. Water Resour. Res., 27,1899-1906.

Rowntree, P.R. and J.A. Bolton (1983). Simulation of the atmospheric response to soil moisture anomalies over Europe, Q.J.R.Met.Soc., 109, 501-526.Schlosser, C.A., and P.C.D. Milly, 2002: A model-based investigation of soil moisture predictability and associated climate predictability. J. Hydrometeor., 3, 483-501.

Sellers, P.J., Y. Mintz, Y.C. Sud, and A. Dalcher (1986). A simple biosphere model (SiB) for use within general circulation models. J. Atmos. Sci., 43, 505-531.

Vinnikov, K., A. Robock, N.A. Speranskaya, and C.A. Schlosser (1996). Scales of temporal and spatial variability of midlatitude soil moisture. J. Geophys. Res., 101, 7163-7174.

Walker, J.M. and P.R. Rowntree, 1977: The effect of soil moisture on circulation and rainfall in a tropical model, Q. J. Roy. Meteor. Soc., 103, 29-46.

Walsh, J.E., W.H. Jasperson, and B. Ross (1985). Influence of snow cover and soil moisture on monthly air temperature, Mon. Wea. Rev., 113, 756-768.Xue, Y.-K., P.J. Sellers, J.L. Kinter and J. Shukla, 1991: A simplified biosphere model for global climate studies. $J$. Clim., 4, 345-364.

Yeh, T.C., R.T. Wetherald, and S. Manabe (1984). The effect of soil moisture on the shortterm climate and hydrology change-A numerical experiment. Mon. Wea. Rev., 112, 474490. 